\title{
GLOBALIZACIÓN Y GEO(TEO)POLÍTICA DE LA HISTORIA: FRANZ ROSENZWEIG Y CARL SCHMITT
}

\author{
GLOBALIZATION AND GEO(THEO)POLITICS \\ OF HISTORY: FRANZ ROSENZWEIG AND CARL \\ SCHMITT
}

\author{
Roberto NAVARRETE AlONSO* \\ Universidad Complutense de Madrid
}

\begin{abstract}
ResUmen: El presente trabajo constituye una contribución a la biografía intelectual de Franz Rosenzweig. Frente a la habitual división de su trayectoria espiritual, se establece un vínculo entre Hegel y el Estado (1914) y La estrella de la redención (1921) por medio de sus Escritos sobre la guerra (1917). Con este fin, se analiza la interpretación rosenzweiguiana de la Primera Guerra Mundial, en clave geopolítica, como el comienzo de un proceso de globalización del mundo. A partir de la crítica de Rosenzweig a la Realpolitik bismarckiana, se expone su concepción del mencionado proceso como camino cristiano hacia la redención y se la compara con la doctrina de los grandes espacios de Carl Schmitt. Por último, se presenta la solución de Rosenzweig al gnosticismo de Marción, a saber, su concepción relacional de judaísmo y cristianismo como agentes de la redención.
\end{abstract}

Palabras Clave: Globalización, geo(teo)política, historia universal, Franz Rosenzweig, Carl Schmitt.

\footnotetext{
* Investigador Juan de la Cierva; Departamento de Historia de la Filosofía, Estética y Teoría del Conocimiento, Facultad de Filosofía, Universidad Complutense de Madrid, Ciudad Universitaria, 28040 - Madrid; E-mail: roberto.navarrete@ucm.es. Proyecto de Investigación Biblioteca Saavedra Fajardo (V). Populismo versus republicanismo: el reto politico de la segunda globalización (FFI2016-75978-R).
} 
AвsтRACT: This paper constitutes a contribution to Franz Rosenzweig's intellectual biography. It aims to establish a connection between Hegel and the State (1914) and The Star of Redemption (1921) by means of Rosenzweig's Writings on War (1917) and in contrast to the usual division of Rosenzweig's intellectual development into two irreconcilable blocks. To this end, Rosenzweig's geopolitical interpretation of the First World War as the beginning of a process of world globalization is presented. Taking as its starting point Rosenzweig's critique of Bismarck's Realpolitik, this process is expounded as the Christian path towards redemption and is compared to Carl Schmitt's Großraum theory. Lastly, Rosenzweig's solution to Marcion's Gnosticism, namely his relational conception of Judaism and Christianity as mutually dependent redemptive agents, is briefly described.

KEYwords: Globalization, geo(theo)politics, universal history, Franz Rosenzweig, Carl Schmitt.

\section{Introducción}

El objeto del presente trabajo consiste, en primer lugar, en rehabilitar la importancia de los Escritos sobre la guerra (1917) de Franz Rosenzweig, esto es, de sus "escritos políticos de juventud» (Rosenzweig, 1979: 1117), en el marco de su producción intelectual. Se establecerá de este modo un vínculo entre Hegel und der Staat (publicado en 1920, pero redactado en lo esencial antes de agosto de 1914) y Der Stern der Erlösung (1921), sus dos grandes contribuciones a la historia de las ideas y a la filosofía respectivamente ${ }^{1}$. Sin el establecimiento de este vínculo podría incluso parecer que los autores de uno y otro libro fueron dos contemporáneos homónimos. Mi propósito es interpretar la diferencia entre «ambos», no como el resultado de una ruptura, sino de la constante tensión entre lo judío (metapolítico y metahistórico) y lo alemán (político e histórico). Esta tensión es característica del pensamiento rosenzweiguiano al menos desde el otoño de 1913, momento en que Rosenzweig, luego de haber tomado la determinación de arrojarse en los brazos de la germanidad, a través del bautismo, acaba por decidir permanecer siendo judío en un entorno alemán, enfrentándose de

\footnotetext{
${ }^{1}$ De la primera de estas obras no hay aún traducción al castellano, salvo de sus conclusiones (Rosenzweig, 2007: 73-82). Sí, en cambio, de la segunda, a cargo de Miguel García-Baró, quien asimismo ha dedicado magníficas páginas a Rosenzweig, tanto a modo de Introducción a La estrella de la redención (1997: 11-39) como en el marco de una serie de ensayos sobre pensamiento judío (2007: 229-312). Respecto de la recepción en castellano de Hegel y el Estado, merece la pena señalar aquí una reciente aportación de José Luis Villacañas, a propósito de la crisis de la República de Weimar (2016b: 383-404).
} 
este modo tanto a la tendencia asimilacionista del liberalismo judío, representado de manera preminente por Hermann Cohen, como al sionismo, entre otros, de Martin Buber (Mendes-Flôhr, 2004: 91-112)². A través de esta contextualización del origen del nuevo pensamiento rosenzweiguiano se ofrecen asimismo las condiciones para una interpretación política de La estrella de la redención y, en concreto, de la tercera de sus partes.

La recepción del pensamiento rosenzweiguiano no puede dejar de lado el «aspecto alemán» de la identidad del autor de La estrella sin al mismo tiempo traicionarlo. En efecto, Rosenzweig debe ser considerado el último representante de la larga tradición de pensamiento judío alemán inaugurada por Moses Mendelssohn en el siglo XviII (Ben-Chorin, 1988: 57-64). Desde este punto de vista, entonces, cuando se intenta explicar el origen del opus magnum rosenzweiguiano, no cabe dejar de referirse -junto a la crisis existencial y de fe vivida por Rosenzweig en 1913- al impacto que causó en él la primera catástrofe europea del siglo xx: aquella Gran Guerra de 1914 que a la postre se convirtió en la Primera Guerra Mundial. En la misma medida, sin embargo, debe también tomarse en consideración la explícita tematización de la guerra por parte de Rosenzweig, es decir, su interpretación de la relación entre política, historia y mundo, no en vano uno de los tres elementos, facticidades (Tatsächlichkeiten) o protofenómenos (Urphänomene), junto con Dios y el hombre, en cuyo despliegue conforme a la ruta creación-revelación-redención consiste, ya en La estrella, el ser de lo real. La expresión "geo(teo)política de la historia», que aparece en el título de este trabajo, trata de mentar la relación en cuestión. La aparición, junto a ella, del término "globalización», quedará justificada en lo que sigue, si bien puede ya mencionarse la circunstancia de que, como es natural, tiene que ver con el título

\footnotetext{
${ }^{2}$ Rosenzweig, en efecto, fue muy crítico tanto con su maestro Cohen y su concepción de la existencia de una correlación esencial entre la germanidad y el judaísmo (Rosenzweig, 1984: 169-175), como con la teología buberiana del pueblo judío (Rosenzweig, 2014: 323-337). El autor de La estrella no publicó nunca su crítica a Cohen, a quien admiraba de manera sincera y profunda, como testimonia su introducción a los Jüdische Schriften del filósofo de Coswig, traducida al castellano por Miguel García-Baró (Rosenzweig, 1998: 13-64). Respecto de Buber, debe ser mencionado el hecho de que, como en el caso de Gershom Scholem, su sionismo no fue de corte meramente político, à la Theodor Herzl, sino de naturaleza cultural. No en vano, tanto Buber como Scholem fueron destacados miembros del movimiento Brit Shalom (en castellano, "Pacto por la paz») y promovieron -sin éxito- la creación en Palestina de un Estado binacional, árabe y judío (Buber, 2009). Como veremos que, según Rosenzweig, fue el caso de Alemania en la Primera Guerra Mundial, también en Palestina terminó por imponerse la Realpolitik estatal-nacional, en 1948, frente al idealismo político de estos intelectuales judíos de primer orden.
} 
del último de los Escritos sobre la guerra de Rosenzweig, a saber, Globus. Estudios sobre la doctrina histórico-universal del espacio (2015: 115-204).

Tal y como aclaró él mismo, Rosenzweig expuso una "teoría de la guerra» (2005: 43) al final del primer libro de la tercera parte de La estrella. La sección en cuestión lleva por título «Los pueblos del mundo: política mesiánica» (1997: 389ss). Representa un desarrollo de la carta que Rosenzweig, en el transcurso de un fascinante intercambio epistolar con Eugen Rosenstock a lo largo de 1916, envió a este último el 7 de noviembre de ese mismo año (Rosenzweig, 2017: 95ss). Sin embargo, su aproximación teórica al más decisivo y grave fenómeno político hunde sus raíces en una serie de once textos sobre política -e historia-, redactados por Rosenzweig en 1917 y publicados en vida de su autor sólo de manera parcial y bajo seudónimo. Estos Jugendschriften estuvieron sin lugar a dudas determinados por la experiencia personal de Rosenzweig en la Gran Guerra, en cuyo frente sudoriental, balcánico, participó, pero también por sus estudios de historia en la Universidad de Friburgo de Brisgovia, cursados entre 1908 y 1912. Por lo general, en efecto, cuando se habla de él como autor de $L a$ estrella de la redención apenas se presta atención al hecho de que, en primera instancia, Rosenzweig fue un discípulo del gran historiador e historiógrafo alemán Friedrich Meinecke: un historiador, por tanto, que en 1913 estaba ya preparado para una habilitación a la que terminaría por renunciar.

El propio Rosenzweig favoreció esta desatención, sobre todo, por medio de algunos pasajes de su correspondencia. En primer lugar, quizá, precisamente en su célebre carta a Meinecke, con fecha de 30 de agosto de 1920, en la que Rosenzweig renunciaba al puesto en la universidad que su maestro había conseguido para él, para lo cual apelaba a la diferencia de calibre existente entre el autor de La estrella de la redención y el autor de Hegel y el Estado (1979: 678-682). Asimismo, la biografía de Nahum N. Glatzer sobre el pensador de Kassel, titulada Franz Rosenzweig: His Life and Thought (1953), contribuyó de manera decisiva al olvido de los orígenes intelectuales del fundador de la Freies Jüdisches Lehrhaus en Fráncfort del Meno. En sintonía, por lo demás, con los deseos de quienes fueron más cercanos a Rosenzweig en vida -en concreto su esposa, Edith, así como su gran amigo Ernst Simon-, quienes a la muerte del pensador trataron de favorecer por encima de todo su imagen de maestro judío, Glatzer presenta a Rosenzweig en su obra, una suerte de hagiografía, como si el filósofo judío de $L a$ estrella poco o nada tuviese que ver con el historiador alemán que, durante cerca de seis años (entre 1908 y 1914), se había ocupado de la génesis y el desarrollo de la idea de Estado en Hegel. Contra el mito fundacional de la recepción póstuma 
de Rosenzweig que representa el relato de Glatzer, en todo caso, se han elevado ya, durante los últimos ańos, importantes y justificadas críticas, relativas ante todo al significado de la crisis de 1913 en la biografía intelectual de Rosenzweig (Pollock, 2012 y 2014). Por razones de espacio no es posible detallar aquí estas objeciones, si bien es de recibo recordar que la labor del recién mencionado Benjamin Pollock, como antes Stéphane Mosès, ha abierto un nuevo horizonte en el campo de las investigaciones sobre Rosenzweig. La presente contribución se inserta en esta línea de la recepción del pensamiento rosenzweiguiano y dirige la mirada de los estudiosos de la obra de Rosenzweig -o de los interesados en ella- hacia sus escritos políticos.

\section{Historia como catástrofe}

El Prólogo y las Conclusiones de Hegel y el Estado (2010: 11-19, 526-533), añadidos por Rosenzweig en 1920 con vistas a la publicación de la obra, dan claro testimonio de la experiencia de la historia como catástrofe característica del pensamiento rosenzweiguiano ${ }^{3}$. Rosenzweig desbordaba así los límites de la historiografía y dirigía la mirada del lector, más allá de Hegel, y del Hegel, hacia La estrella y la redención (Navarrete y Lanceros, 2015: 205-225). El grito con el que comienza La estrella (Rosenzweig, 1997: 43ss), es decir, el grito del Yo que, enfrentado a su propia muerte, se topa con lo Inexorable, resuena también en estas líneas del libro que, antes de la guerra, su autor había concebido como mero escrito de habilitación. Sin embargo, las palabras, tomadas de la oda de Hölderlin An die Deutschen, que presiden las consideraciones finales de Hegel y el Estado, parecen vincular más bien este libro al historicismo de quien fue el primer maestro de Rosenzweig y, en particular, a su investigación sobre los orígenes del Estado nacional alemán: Weltbürgertum und Nationalstaat, cuya lectura, allá por 1908, había inspirado de hecho el trabajo de Rosenzweig como historiador de las ideas (Rosenzweig, 2010: 18).

"...aus Gedanken die Tat...", es decir, "...del pensamiento, la acción...» (Rosenzweig, 2010: 526). El lema elegido por Rosenzweig para presentar su diagnosis de lo acontecido en Alemania desde la muerte de Hegel hasta el final

\footnotetext{
${ }^{3}$ Una experiencia que Walter Benjamin compartió con su admirado Rosenzweig, algunos años -y una guerra mundial- más tarde, como atestigua su testamento vital e intelectual (Benjamin, 2008: 303-318). Rosenzweig dejó constancia explícita de su concepción de la historia como catástrofe en sus «esbozos de un nuevo pensamiento» (2014: 239s, 246s).
} 
de la (Primera) Guerra Mundial, pasando como es natural por la gran década de Bismarck, pone de relieve la ascendencia metodológica del trabajo del historiador que, un lustro antes de que estallara la guerra, había emprendido la tarea de estudiar el pensamiento hegeliano del Estado con la esperanza puesta en la apertura, tanto ad intra como ad extra, del futuro del pueblo alemán (Rosenzweig, 2010: 17s). El Motto de las conclusiones del Hegel revela el compromiso de Rosenzweig con el método genealógico empleado por su Doktorvater en su libro sobre la génesis del II Reich, así como el propósito común de sus respectivas investigaciones: la elaboración de una suerte de ontología política del presente a partir de los impulsos procedentes de la esfera intelectual que habían guiado -y legitimado- la historia política alemana -en especial entre 1871 y 1918-. Meses después, en junio de 1919, la nueva República hubo de firmar un ultrajante -e incriminatorio- tratado de paz en el mismo lugar en el que, cerca de medio siglo antes, el Canciller de Hierro, acaso demasiado tarde (Plessner, 2017), había conseguido un lugar en el pluriversum estatal-nacional europeo para (una parte de) la nación alemana: la Gran Galería del Palacio de Versalles.

Dos guerras mundiales, pues, se reflejaron durante el siglo Xx en los espejos de aquella suntuosa sala. Rosenzweig sólo fue testigo del primero de estos desgraciados desastres europeos. Localizó la causa de la guerra mundial que más tarde se convirtió en la Primera, pero al hacerlo apuntó al mismo tiempo hacia el motivo último de la Segunda: la estrechez de la idea estatal-nacional, ampliada de manera ficticia y ponzońosa como Imperio nacional aspirante a la realización de una idea (o imagen) de mundo cuya candidatura era avalada y elevada nada menos que por el propio destino histórico-universal -entendido de modo asimismo estrecho-. Se trataba en definitiva de una irremediable colisión entre diferentes políticas mesiánicas en pugna por realizar en la historia su propio Reino de los Cielos, es decir, enfrentadas por el establecimiento de una organización unitaria del poder humano con objeto de planificar, dirigir y dominar, sin fisuras, sin fronteras, la Tierra toda.

Aquello en lo que antes de 1914 Meinecke había visto el gran éxito histórico-político de la germanidad, es decir, la realización de la idea estatal-nacional de cuño supuestamente hegeliano, representó para Rosenzweig, al término del conflicto, una traición cometida tanto contra Hegel como contra el futuro que Goethe había imaginado para su pueblo: la consumación de la determinación centroeuropea de la nación alemana, esta vez al margen de toda Machtpolitik. Tal era según Rosenzweig el aire fresco que, en lugar de la saturada atmósfera bismarckiana, debió haber respirado el Reich. Tal era, en definitiva, la meta 
de la guerra de 1914 (Rosenzweig, 2015: 91-95), una esperanza de la que en 1920 no quedaba ya nada más que escombro, broza y cascote (Rosenzweig, 2010: 18). Para Rosenzweig, en todo caso, Hegel se ubicaba sólo al principio de este camino (2010: 526s). En su final se encontraba Bismarck y, luego de su desaparición política, el gigantesco espectro de la Realpolitik que impidió que el pueblo alemán vislumbrara siquiera el que, tras su irrupción en el escenario político mundial, era su más alto (y amplio) destino histórico-universal. Uno que no era simplemente político, o que en todo caso no lo era en el sentido de la identidad, sin resto, de Estado y nación, la cual habría quedado sobrepasada con carácter definitivo, según Rosenzweig, en virtud del estallido mismo de la guerra mundial. La nueva tarea de Alemania era más bien, conforme a la imagen rosenzweiguiana del mundo, la de generar las condiciones de posibilidad de la unidad estatal supranacional $-\mathrm{y}$, en este sentido al menos, metapolítica- a la que se refería el término Mitteleuropa (Rosenzweig, 2015: 167ss).

En lo que sigue se hará referencia a cuatro de los escritos políticos del joven Rosenzweig. El primero de ellos fue titulado por su autor, precisamente, «Realismo político" (2015: 43-50). Junto a este texto se prestará atención asimismo a El nuevo Levante (2015: 97-106) y Noroeste y sudeste (2015: 107-113), los cuales, de acuerdo con Rosenzweig, pertenecen a su gran monografía sobre geopolítica de la historia universal: Globus (2015: 115-204). Todos ellos, a su vez, fueron considerados por su autor complementos de su libro sobre Hegel (1979: 398), con razón, pues Rosenzweig presenta en ellos aquello que expondrá más tarde, de manera sintética, en el Prólogo y las Conclusiones del Hegel. En particular, si el objetivo de su primer libro debió ser descomponer ante los ojos del lector el desarrollo, a través de la vida del princeps philosophorum, de «la dura y restrictiva idea hegeliana del Estado» (Rosenzweig, 2010: 18), a partir de 1917 Rosenzweig trató, en primer lugar, de denunciar el fracaso del realismo político de cuño bismarckiano, y, en segundo lugar, de exponer el contenido de su gran esperanza metapolítica: la configuración, en Mitteleuropa, de un gran espacio - por mentarlo con la expresión acuñada con posterioridad por Carl Schmitt- situado entre el Oriente ruso-eslavo y el Occidente franco-británico, que fuese capaz de aglutinar la multiplicidad de las naciones centroeuropeas y, así, de hacer efectiva la superación del Estado nacional que el discípulo de Meinecke quiso ver anunciada en la Gran Guerra. 


\subsection{Más allá de Bismarck: Mitteleuropa como destino histórico de Alemania}

Rosenzweig interpreta la Realpolitik bismarckiana y su gran logro, la unificación política de la nación cultural alemana, como una estatal-nacionalización de la política ideada por Hegel que, aunque adaptada a la realidad histórica de la segunda mitad del XIx, no habría estado ya a la altura, sin embargo, de la misión histórico-universal a la que el nuevo sujeto político, Alemania, hubo de enfrentarse en la Primera Guerra Mundial con vistas a la conservación de su propia existencia y, por lo tanto, de su propio futuro. En lugar de inspirar a la nueva unidad política para que trascendiera los estrechos y egoístas intereses del Reich y uniera su destino al del mundo, la Realpolitik de Bismarck, a través de sus sucesores, celebró según Rosenzweig esa estrechez y ese egoísmo como valores sacrosantos y absolutos. Tuvo su sentido y su valor, incluso necesidad interna, pero sólo hasta 1871. Desde entonces, el joven soldado judío alemán veía en ella, es decir, en la "política de las facciones individuales carentes de relación» (Rosenzweig, 2015: 47), tan solo una debilidad, responsable en última instancia de la penosa situación de Alemania. Ofrecía la razón por la que ésta dejó de ser capaz de nombrar sus nuevas necesidades y, por lo tanto, de fijar su satisfacción como su objetivo más propio, o el motivo por el que la Alemania post-bismarckiana fue incapaz de dar respuesta a la nueva realidad que había surgido, ahora sí, del sentimiento del pueblo: Deutschland, cuyas condiciones de posibilidad, en cambio, sí había logrado crear, aun clam vi et precario, la astucia política y la estrategia militar del Canciller de Hierro. Dicha realidad condujo al pueblo alemán hacia la batalla como respuesta, ya no a una llamada individual, sino del todo y por el todo: Deutschland über alles. En el momento de verse obligada a luchar por su nuda vida, Alemania poseía ya con pleno derecho y absoluta conciencia lo que Bismarck sólo pudo crear de manera astuta, disimulada y violenta: un alma propia y su correspondiente meta política, a saber, la determinación «centroeuropea» que la pequeña lengua de la astucia propia del realismo político era incapaz de nombrar y, por consiguiente, de asumir como el destino histórico-universal de Alemania.

Si el realismo político bismarckiano generó en 1871 las condiciones de posibilidad de una politización de la nación alemana, así como, por tanto, de su participación en la historia universal en sentido hegeliano, esa misma Realpolitik, mantenida en el tiempo por los sucesores del fundador del Estado nacional alemán, fue incapaz en razón de su propia naturaleza de responder de modo satisfactorio a la grandeza de la situación histórico-universal y el destino de la individualidad histórica por ella creada. La acción política de Alemania adoleció, según el análisis de 
Rosenzweig, de una nefasta estrechez de miras: apegada a una realidad divinizada, la del Estado nacional, le fue imposible retornar al plano de la idea y, desde ella, regresar nuevamente al mundo en que la propia idea exigía realizarse de manera efectiva. Desatendió el esplendor y la grandeza de la nueva época a la que la guerra pudo dirigir a Alemania en caso de que ésta hubiera seguido una política acorde a los nuevos tiempos. De este modo, condujo a la unidad política alemana hacia el desastre sancionado en Versalles: no un ensanchamiento espiritual, político y espacial, sino un estrechamiento si cabe aún mayor a aquel que, en opinión de Rosenzweig, caracterizaba al pueblo alemán ya antes de la guerra (1979: 613). Rosenzweig apunta en cambio hacia una revisión de la idea de Estado nacional: hacia el futuro de un Estado multinacional.

\subsection{Crítica geopolítica de la Realpolitik}

El síntoma de esta nueva misión histórico-universal de Alemania vino dado según Rosenzweig por la tendencia geopolítica inaugurada por la guerra: la aparición de una serie de configuraciones políticas que, a partir de un eje que atravesaba Europa desde el noroeste hacia el sudeste, gobernaba desde entonces la historia europea en general y la alemana en particular. Tal es el escenario político contemporáneo de Rosenzweig, de cuyos orígenes, suprimido en lo fundamental el motivo de la guerra, es decir, dado únicamente el desfile de sus causas, trataba Globus (Rosenzweig, 1979: 334; 346s). Y tal es asimismo la cuestión a la que Rosenzweig se enfrenta en los escritos denominados en sus cartas como Macedonikusaufsätze: Noroeste y sudeste y El nuevo Levante. La tesis defendida por Rosenzweig en estos artículos escritos desde las trincheras de Macedonia puede ser resumida como sigue: si sudoeste y noreste fueron los polos entre los que se tensaron la historia alemana y la historia europea en el siglo XIx, la contraposición geográfica que determinó la orientación de la política alemana y europea en el siglo de Bismarck y hasta el umbral de la guerra, en el momento en que ésta estalló una línea por completo distinta, opuesta de manera diametral, atravesaba Alemania y Europa. Se trata de la contraposición, así lo resume Rosenzweig, "Amberes-Constantinopla» (2015: 100). En la dinámica política interna de Alemania, esta contraposición significó la superación de la contraposición entre Prusia y el sur de Alemania propia del periodo de la unificación ${ }^{4}$.

\footnotetext{
${ }^{4}$ «Superación», en todo caso, no en el sentido de que la oposición fuese liquidada, sino en el de que se vio desprovista de significado histórico, en la medida que cedió su lugar a una contraposición geopolítica más determinante (Rosenzweig, 2015: 98s).
} 
El realismo político, que tan buen servicio había prestado a Bismarck para dominar la tensión entre Berlín, de un parte, y Fráncfort-Stuttgart de otra, debía ser ahora superado a fin de que Alemania pudiese asumir el liderazgo en el nuevo eje geopolítico o, cuando menos, a fin de que pudiera hacerse con un lugar en él. De acuerdo con Rosenzweig, entonces, el desajuste del realismo político bismarckiano es tanto temporal, histórico si se quiere, como espacial, geopolítico -si es el caso que geopolítica e historia pueden ser de veras distinguidas-. Si la línea noreste-sudoeste tuvo como palabra clave el término Realpolitik, la reorientación de las tensiones políticas en Alemania y Europa obligaban a la primera, según Rosenzweig, a redirigir su política más allá de sus fronteras, hacia Mitteleuropa. Esta «reorientación» se cifraba en que el lugar que en el tiempo de las representaciones bismarckianas había ocupado el sur de Alemania debía ocuparlo ahora el «sudeste fuera de Alemania» (Rosenzweig, 2015: 103). Tal es el camino que, dejando a un lado el noreste de Europa (Polonia), habría permitido a Alemania, en opinión de Rosenzweig, hacerse cargo del problema de la organización política de Centroeuropa y probar así la fuerza y la profundidad del espíritu del pueblo alemán en la perspectiva de una tarea distinta, en ningún caso sólo política: la generación de un nuevo orden centroeuropeo que garantizase un futuro para Alemania sin necesidad de recurrir, como acabaría sucediendo, a una segunda guerra de dimensiones mundiales. Se trataba también y en lo fundamental de una «europeización» (Rosenzweig, 2015: 112s) del sudeste del continente europeo, dominado durante siglos por el imperio otomano, así como de la propia media luna turca. Dicha europeización debía ser respetuosa tanto desde un punto de vista político como cultural con aquellos débiles pueblos que, carentes de Estado, habían sido súbditos de la potencia otomana, así como con la emergente nación turca. La propuesta centroeuropeísta de Rosenzweig se cifraba, en definitiva, en una democratización del sudeste europeo basada en la idea del derecho a la autodeterminación y en teoría respetuosa, por tanto, con las religiosidades y las nacionalidades de los pequeños pueblos centroeuropeos: los pueblos balcánicos y, en último término, Turquía.

De acuerdo con la nueva orientación geopolítica de la historia, el tener lugar de los acontecimientos históricos decisivos incluso desde antes de 1914 en la dirección de la contraposición geopolítica entre Amberes y Constantinopla, el significado de la Primera Guerra Mundial para los pueblos centroeuropeos y, en primer lugar, para Alemania, se resuelve así según Rosenzweig en una exigencia metapolítica de acuerdo con la cual las grandes naciones centroeuropeas debieron abandonar la vieja figura del Estado nacional, sobrepasada por la historia, y pasar a formar parte, junto con las pequeńas naciones surgidas de la desaparición de 
la Doppelmonarchie austro-húngara y del imperio otomano, de una gran unidad política de carácter supranacional. En ello consistía la misión histórico-universal a la que se enfrentaban los pueblos centroeuropeos, así como, por lo tanto, la razón de ser de la crítica rosenzweiguiana a una Realpolitik determinada por una estrecha concepción del Estado cuyo desarrollo, iniciado alrededor de 1800, había visto el comienzo de su fin en 1914 (Rosenzweig, 2015: 167) 5 .

\section{El problema «filosófico-histórico» de la unidad del mundo}

La superación del Estado nacional, defendida por Rosenzweig en sus Macedonikusanfsätze, conduce a una doctrina espacial de la política, es decir, a una geopolítica, que, tras la Segunda Guerra Mundial, un jurista como Carl Schmitt llamaría "doctrina de los grandes espacios» ${ }^{6}$. Resulta cuando menos llamativo que dos personalidades tan distintas, las cuales apenas supieron la una de la otra, coincidiesen a la hora de comprender la gran política del siglo xx desde el punto de vista de la ampliación territorial de las unidades políticas. La influencia teórica de Schmitt en la reconfiguración del orden mundial tras el colapso del III Reich es de sobra conocida: tanto Alexander Kojève, que concibió en 1945 la idea de un imperio latino, como Ernst Jünger, en cuyo escrito sobre La paz propuso la unión de los Estados europeos en una única gran unidad política, habían tomado en cuenta los escritos schmittianos sobre geopolítica. Lo más probable es que no conociesen en absoluto los Macedonikusaufsätze de Rosenzweig y no cabe la menor duda de que no habían leído Globus, toda vez que este valiosísimo trabajo vio la luz por vez primera en 1984. Los Estudios sobre la doctrina históricouniversal del espacio, reunidos por Rosenzweig a finales de 1917 bajo el título Globus, están sin embargo emparentados de manera íntima, desde un punto de vista temático, con las tesis de Schmitt sobre El nomos de la Tierra (1950), así como sobre el papel histórico-universal de la confrontación de los elementos Tierra y mar (1942).

\footnotetext{
${ }^{5}$ La crítica, por lo demás, no iba dirigida sólo contra Hegel, Bismarck y sus seguidores, sino por supuesto también contra Meinecke (Rosenzweig, 1979: 459) y, por cierto, contra Cohen y su concepto de "federación de Estados» (Staatenbund), el cual, a juicio de Rosenzweig, presupone la pervivencia de los Estados nacionales (1979: 182).

${ }^{6}$ Sobre la Großraumlehre debe consultarse, al menos, los ensayos de Carl Schmitt recogidos en la tercera parte del volumen Staat, Großraum, Nomos (1995: 225-482). José Luis Villacañas se ha ocupado de esta cuestión en su libro Poder y conflicto (2008: 248 ss.).
} 


\subsection{Globalización como deseuropeización del mundo}

No en vano, Rosenzweig dividió su contribución a la geopolítica históricouniversal en dos capítulos dedicados, de manera respectiva, a los elementos terrestre y marítimo del mundo (y de su historia), a saber, al mundo de los Estados y a la posibilidad de un Estado mundial, por un parte, y al dominio sobre las aguas y la libertad de los mares, por otra. Este segundo estudio, titulado Thalatta, no había sido aún proyectado por Rosenzweig cuando, el 5 de enero de 1917, comenzó a escribir lo que más tarde se convertiría en la primera parte de Globus, esto es, Ecumene (Rosenzweig, 1979: 337). En un primer momento, de hecho, su proyecto tenía que ver ante todo con Europa, entendida como escena de la historia de las potencias mundiales europeas, como si el Theatrum Europaeum fuese el único escenario de la historia universal (Rosenzweig, 1979: 334s). Formulado de otro modo: como si el mundo perteneciese aún a Europa. Rosenzweig sólo empezó a escribir Thalatta después de que EE. UU. entrase en la guerra y, de este modo, irrumpiera en el marco de la historia universal como potencia mundial no europea. La participación estadounidense en la guerra mundial significó para Rosenzweig que el mundo había dejado de ser europeo: una globalización del mundo, en definitiva. Éste, como su historia, ya no era Europa, es decir, una mera parte, sino un todo completo: una Sphaira -tal fue en un primer momento el título del conjunto de Ecumene y Thalatta- o un Globus (Rosenzweig, 1979: 495s, 503s). A partir de abril de 1917, Ecumene se hizo imposible, insuficiente, y Thalatta hubo de ser redactada, de tal manera que fuese posible hacer justicia en la obra tanto a América como a Japón (Rosenzweig, 1979: 423s, 497).

Rosenzweig, por tanto, que había reivindicado la europeización de Turquía, fue testigo al mismo tiempo de la des-europeización del mundo que terminaron por confirmar, muerto ya el pensador de Kassel, la Segunda Guerra Mundial y, después, el devenir del mundo desde 1945 hasta nuestros días. Así, en febrero de 1917, Rosenzweig no pudo sino admitir que Hegel había tenido razón al afirmar que América era la tierra del futuro: un futuro que la entrada de EE. UU. en la guerra había transformado en presente (Rosenzweig, 1979: 355). La confirmación de la des-europeización del mundo resultó por tanto ser al mismo tiempo una verificación de la concepción hegeliana de la historia. Al menos hasta cierto punto, ya que, frente a Hegel (y Ranke), Rosenzweig evita toda glorificación de la historia y no la considera una teodicea, sino una mera cuestión de hecho (Rosenzweig, 1979: 499-501; 113; Lucca y Navarrete, 2016: 303-319). No analiza el devenir histórico como la curva entre las coordenadas tiempo-alma, es decir, desde el punto de vista del Espíritu, sino entre las coordenadas tiempo-espacio, 
o sea, como movimiento, y por cierto en una determinada dirección: la ilimitada profundización del asimismo ilimitado último Nosotros hacia el último Yo (Rosenzweig, 2015: 117), es decir, hacia el Dios único, cuya consumación se produce en el último momento de la historia. El Dios de la redención se realiza, no a través de la historia, sino en su final, pero no cabe duda de que, para Rosenzweig, el proceso histórico-universal representa un signo de la venida del Reino. De acuerdo con el autor de La estrella, al Reino de Dios corresponde la unidad del mundo: el globo completo hacia el que tiende la superación del Estado nacional. El surgimiento de unidades políticas cuyo territorio se extiende más allá del territorio de la nación, es decir, el surgimiento de grandes espacios en el sentido posterior de Schmitt, suscitaría así una nueva época de la historia universal que, sin embargo, no es tampoco definitiva, sino tan pasajera como la era del Estado nacional.

\subsection{Franz Rosenzweig versus Carl Schmitt}

La diferencia entre el significado histórico-universal de la geopolítica de Rosenzweig y el de la doctrina de los grandes espacios de Schmitt se cifra en este punto. Mientras que, por medio del establecimiento de un orden mundial basado en el equilibrio de diversas unidades políticas supranacionales, el jurista trataba de retener el transcurso de la historia hacia su final, o sea, trataba de permanecer en la historia en tanto que escenario mundial de lo político, Rosenzweig estaba convencido de que el eschaton resulta en verdad incontenible y consiste, no en vano, en la superación de aquello político. Quien intenta retener el eschaton, intenta al mismo tiempo evitar la redención del mundo y se contenta con el nivel superficial, terrestre, de la diferencia amigo-enemigo, en lugar de aspirar a la realización de la ciudad celeste de la que es símbolo la profunda unidad de los océanos. Por tanto, en lo fundamental puede afirmarse que, mientras que Schmitt se posiciona de parte de la tierra como katechon del final de la historia, Rosenzweig se decide, por el contrario, en favor del mar en tanto que símbolo de una venidera unidad del mundo, es decir, en tanto que símbolo del eschaton mismo. Salta a la vista, sin embargo, que ambos están de acuerdo en que la globalización del mundo representa una tendencia despolitizante. A ojos de Schmitt, esta despolitización equivale asimismo a una deshumanización, conforme a la definición aristotélica del ser humano como zoon politikon. Para Rosenzweig, en cambio, a una antropología pagana debe corresponder, de manera necesaria, una imagen del mundo asimismo pagana, a saber, la imagen «homérica» del mundo (Rosenzweig, 2015: 176s). A su juicio, una consideración más profunda de la 
historia hace corresponder al mundo histórico la imagen «bíblica» de la unidad del mundo, porque, afirma Rosenzweig, «Dios, de quien está escrito que fue un hombre de guerra, creó únicamente un cielo y una tierra» (2015: 173). De manera consecuente, Rosenzweig no reduce el ser humano a la condición de homo politicus (personalidad), sino que al hombre es consustancial al mismo tiempo su carácter de sí-mismo, esto es, de homo revelationis (Rosenzweig, 1997: 101ss, 201 ss). El Estado, por tanto, no es malo en sí mismo hasta que no resulte superficial, esto es, hasta el acaecer del último acontecimiento (Rosenzweig, 1979: 656).

\subsection{Judaísmo y cristianismo como factores teológico-políticos}

De igual modo, resulta innegable el hecho de que tanto la geopolítica de la historia de Schmitt como la de Rosenzweig representan una geo-teo-política de la historia universal. En el caso de Schmitt, la tierra (el asentamiento y la ordenación: Ortung y Ordnung) corresponden al catolicismo, mientras que el mar (el des-asentamiento y el desorden: Behemot) corresponde al protestantismo (en puridad, a Inglaterra en tanto Isla) y, ante todo, al judaísmo, cuya meta consistiría en acelerar el final de lo político. Por esta razón, la estrategia katechóntica de Schmitt es profundamente antijudía, como su genealogía de los enemigos del Leviatán de Hobbes (Schmitt, 2004: 47ss) ${ }^{7}$. En el caso del judío Rosenzweig, por el contrario, el judaísmo permanece al margen de la historia del mundo, está ya en su meta, mientras que la cristiandad, es decir, los pueblos del mundo, permanecen aún en camino hacia la redención y, en consecuencia, están en el mundo como portadores de la historia universal. Sin embargo, las respectivas relaciones de cristianismo y judaísmo con el todavia-no (Noch-nicht) y el ya (Schon) se invierten cuando la Cruz y la Estrella dejan de ser consideradas desde el punto de vista de la historia y pasan a serlo desde la perspectiva del acaecer de la redención. Pues, para el judaísmo, el acontecimiento no ha acontecido aún, mientras que para el cristianismo el Mesías ya ha venido: $y a$ ha entrado en la historia universal ${ }^{8}$.

\footnotetext{
${ }^{7}$ Tan antijudía, en rigor, como marcionita, tal y como ha defendido de manera brillante Tristan Storme en Carl Schmitt et le marcionisme (2008). Acerca del antijudaísmo schmittiano debe consultarse asimismo Carl Schmitt und die Juden, de Raphael Gross (2005).

${ }^{8}$ Resulta claro, en todo caso, que la propuesta rosenzweiguiana, a diferencia de la schmittiana, es antimarcionita de manera rotunda, pues apuesta por el ecumenismo judeo-cristiano como condición de posibilidad de la redención. Tal es en buena medida, no en vano, el tema capital de la citada correspondencia de 1916 entre Rosenzweig y Eugen Rosenstock (Rosenzweig, 2017). He desarrollado esta cuestión, a saber, la del antimarcionismo rosenzweiguiano,
} 
Verdadero símbolo del Globus no lo es, por tanto, el cristianismo, sino el judaísmo, cuya existencia, a ojos de Rosenzweig, consiste en anticipar la globalización definitiva, redentora, del mundo -que sólo de Dios depende-, en la medida en que el Pueblo Elegido no toma parte en la historia universal, es decir, en la medida en que está en la historia universal como si no estuviera en ella: en la medida en que no posee un Estado ni, por tanto, un espacio, de tal manera que no está en condiciones de fijar ni de desplazar frontera alguna. Por esta misma razón, el judaísmo no desempeña ningún papel en la narración rosenzweiguiana de la ruta histórico-universal hacia el globo. Esta imagen, que se realiza a través de la historia, es ya una imagen judía. Su realización en el mundo y a través de la historia, sin embargo, es la tarea del cristianismo. Consiste, à la Hegel, en la mundanización de la razón a través del Estado, es decir, en el progresivo y universal despliegue de la razón que el acontecimiento cristiano hace posible y, en puridad, exige (Rosenzweig, 2010: 355s). Se trata sin duda de una tarea revolucionaria cuya meta consiste en desplazar las fronteras, es decir, en poner la historia en movimiento. Sin embargo, a cada momento, se topa con fronteras y, por cierto, no sólo con fronteras políticas, sino en último término con los límites del propio ser humano, a saber, con el hecho de que la redención no está a disposición del hombre, sino que sólo el Dios puede redimir el mundo.

\section{Conclusiones}

Sin lugar a dudas, Rosenzweig otorgó una función redentora a la historia universal -y por ende a la política- (Pollock, 2004: 332-353). No negó en términos absolutos la verdad de la metafísica hegeliana de la historia, es decir, de la idea hegeliana de una mundanización del Espíritu, sino el carácter totalizante de esta concepción de la historia. En realidad, tras la verificación de la política mesiánica en la Primera Guerra Mundial, Rosenzweig no estaba ya en condiciones de negar esta verdad hegeliana. El sistema de Hegel, no obstante, constituía

en «Franz Rosenzweig adversus Marción: sinagoga, iglesia, mundo» (Navarrete, 2017). Por lo demás, cabe encontrar una excelente introducción a la versión marcionita del gnosticismo en las obras de Hans Jonas (2000: 161-175) y Antonio Piñero (2007: 85-91). José Luis Villacañas (2016: 179ss.), por último, ha estudiado el origen paulino del marcionismo y su dimensión teológico-política $-\mathrm{y}$, en esa medida, schmittiana-, como antes Jacob Taubes (2007: 69ss.). De este sociólogo de la religión debe destacarse en este contexto sus respectivos ensayos en torno a la controversia entre judaísmo y cristianismo -con especial atención, por cierto, a la posición de Rosenzweig- , y acerca de la historia de la investigación sobre la gnosis y, en particular, sobre Marción (2007b: 87-99 y 182-190). 
para él la expresión filosófica de una verdad cristiana: la historia representa para Rosenzweig el escenario en el que se despliega la religión cristiana. Ahora bien, el cristianismo, desde el punto de vista del autor de La estrella, no lo es todo para la redención, como tampoco lo son la historia ni la política. El todavía-no judío, por lo tanto, no reemplaza la historia de la globalización del mundo, sino que la des-absolutiza, es decir, la desencanta. La función redentora del judaísmo metapolítico y metahistórico consiste, entonces, en des-divinizar y, por ende, secularizar la historia y la política.

El transcurso de los acontecimientos hasta el final de la guerra acabó por conducir a Rosenzweig hacia una decepción política a la que no fue ya capaz de sobreponerse más que situándose en los márgenes tanto del Estado como de la historia: refugiándose en el judaísmo de cuya especificidad dará cuenta en $L a$ estrella de la redención. La guerra civil europea por el dominio del mundo fue por completo determinante en relación a la transformación del autor del Hegel-«un historiador (completamente preparado para la habilitación)»- en el autor de $L a$ estrella -«un filósofo (absolutamente no preparado para la habilitación)» (Rosenzweig, 1979: 680)-. De esta transformación, del tránsito desde una historicista (y hegeliana) concepción histórica del acaecer (típicamente alemana) a su mesiánica concepción metahistórica (típicamente judía), es decir, de una concepción del tiempo como tiempo en el que suceden cosas, o una temporalidad cronológica, a una como tiempo que "por sí mismo acaece» (Rosenzweig, 2005: 29), o una temporalidad diacrónica y relacional, son índice los textos redactados por Rosenzweig con ocasión de la primera gran catástrofe europea de alcance mundial. Como lo añadido en 1920 a su estudio sobre la idea hegeliana de Estado, los escritos de Rosenzweig sobre la guerra señalan el camino que va, ya no de Hegel a Bismarck, sino del Hegel a La estrella y, en particular, al tratado de teología política que cabe encontrar en el tercero de los libros de que se compone, cuyo lema no puede ser más elocuente: In tyrannos!

El hecho de que en el Prólogo del Hegel Rosenzweig indique por dos veces que, a la luz de lo sucedido durante el medio siglo de vida del Reich, no habría comenzado a escribirlo, revela las dificultades que el autor tuvo para identificarse con el texto (Rosenzweig, 2010: 17s; Rosenzweig, 1979: 627, 629s). Quizá apunte también a su posterior caída en el olvido. El caso es que lo mismo había dicho su autor, alrededor de tres años antes, respecto de sus Escritos sobre la guerra, incluido Ecumene. No, por cierto, o no de manera explícita, Thalatta, como tampoco quizá Globus en sentido estricto: la meditación filosófico-histórica que sirve de introducción al conjunto formado por estos «dos capítulos sobre geopo- 
lítica» (Rosenzweig, 1979: 497). La razón de esta imposible identificación del autor con su «obra de juventud» no era otra que el acontecimiento político por el que el pueblo alemán quedó condenado de manera irreversible: la dimisión del Canciller Bethmann-Hollweg, forzada en realidad por los generales Ludendorff y Hindenburg, y su sustitución por Michaelis, el 13 de julio de 1917.

Ese día se esfumó todo el entusiasmo por la guerra que Rosenzweig, como tantos otros, había sentido en 1914. El triunfo de la Realpolitik sobre el idealismo político de Bethmann-Hollweg era el signo definitivo, no ya de que el Reich saldría derrotado de la guerra, sino de que el pueblo alemán había sido incapaz de afrontar su responsabilidad histórico-universal: se dirigía de manera inexorable hacia el oscuro desagüe de una historia -hegeliana, acaso demasiado- de la que ya no podría ser sujeto, sino mero objeto. Esto significó para Rosenzweig un punto de inflexión decisivo en su trayectoria intelectual. Bethmann-Hollweg personificaba el ideario político centroeuropeísta en el que Rosenzweig había depositado las esperanzas a las que todavía aludía en el Prólogo del Hegel con el único objeto ya, no obstante, de dejar constancia de su defunción. Desaparecido el Canciller, Alemania no podía más que esperar el estallido de una nueva guerra que, no vivida ya por Rosenzweig, tuvo consecuencias mayores, acaso irreparables, en especial para sus correligionarios: el exterminio, tanto espiritual como biológico, del judaísmo centroeuropeo y, en primer lugar, del alemán. Del hecho de que Rosenzweig no pudiese ser testigo de esta aparente ruptura en dos de la historia, tanto de la política como de la espiritual, no se sigue que sus advertencias contra la tiranía resulten vanas. Sin caer en la tentación de negarle toda verdad, Rosenzweig ofreció en La estrella una alternativa meta-política y meta-histórica a la absolutización hegeliana de la historia y de los Estados. Una alternativa que se contrapone a tal absolutización como su (mesiánico) resto insuperable.

\section{Bibliografía}

Ben-Chorin, Schalom, «Franz Rosenzweig und das Ende des deutschen Judentums». Der Philosoph Franz Rosenzweig (1886-1929): Internationaler Kongreß-Kassel 1986. Ed. Schmied-Kowarzik, W. Karl Alber: Freiburg, 57-64.

Benjamin, Walter (2008). «Sobre el concepto de historia». Obras (libro I, volumen 2). Madrid: Abada, pp. 303-318.

Buber, Martin (2009). Una tierra para dos pueblos. Escritos políticos sobre la cuestión judeo-árabe. Ed. P. R. Mendes-Flôhr, Salamanca: Sígueme. 
GarCíA-BARÓ, Miguel (1997). «Introducción. La figura de la Estrella. Una perspectiva global para la lectura de Rosenzweig». La estrella de la redención. Salamanca: Sígueme, pp. 11-39.

-(2007). «Meditaciones sobre el Nuevo Pensamiento de Franz Rosenzweig». La compasión y la catástrofe. Ensayos de pensamiento judio. Salamanca: Sígueme, pp. 229-312.

Glatzer, Nahum Norbert $\left(1961^{2}\right)$. Franz Rosenzweig: His Life and Thoght [1953]. New York: Schocken.

Gross, Raphael (2005). Carl Schmitt und die Juden. Eine deutsche Rechtslehre. Frankfurt a.M.: Suhrkamp.

Jonas, Hans (2000). La religión gnóstica. El mensaje del Dios Extraño y los comienzos del cristianismo. Madrid: Siruela.

JüNGER, Ernst (1996). La paz seguido de El nudo gordiano, El estado mundial y Alocución en Verdún. Barcelona: Tusquets.

Kojève, Alexander (1990). «L'Empire latin (Esquisse d'une doctrine de la politique française)» [1945]. La Regle du Jeu 1, pp. 89-123.

Lucca, Enrico, y Navarrete, Roberto (2016). «Vom Gott der Aufklärung zum Gott der Religion: Franz Rosenzweigs Brief an Rudolf Ehrenberg vom September 1910 und sein Kampf gegen die Geschichte als Theodizee». Naharaim. Zeitschrift für deutsch-jüdische Literatur und Kulturgeshichte Vol. 10/2, pp. 303-319.

Meinecke, Friedrich (1908). Weltbürgertum und Nationalstaat. Studien zur Genesis des deutschen Nationalstaates. München-Berlin: Oldenbourg.

Mendes-Flôhr, Paul (2004). Jüdische Identität. Die zwei Seelen der deutschen Juden. München: Fink.

Mosés, Stéphane (1982). Système et révélation: la philosophie de Franz Rosenzweig. Paris: Éd. du Seuil.

NAvarrete, Roberto (2017). «Rosenzweig adversus Marción: sinagoga, iglesia, mundo». Cartas sobre judaísmo y cristianismo. Salamanca: Sígueme, pp. 155-185.

Navarrete, Roberto, y Lanceros, Patxi (2015). «De Hegel a La estrella: ahora, todavía, siempre». Escritos sobre la guerra. Salamanca: Sígueme, pp. 205-225.

Piñero, Antonio (2007). Los cristianismos derrotados. ¿Cuál fue el pensamiento de los primeros cristianos heréticos y heterodoxos? Madrid: EDAF.

Plessner, Helmuth (2017). La nación tardía. Sobre la seducción política del espiritu burgués (1935-1959). Madrid: Biblioteca Nueva.

Pollock, Benjamin (2004). «From Nation State to World Empire: Franz Rosenzweig's Redemptive Imperialism». Jewish Studies Quarterly Vol. 11, pp. 332-353. 
-(2012). «On the Road to Marcionism: Franz Rosenzweig's Early Theology». The Jewish Quarterly Review Vol. 102/2, pp. 224-255.

-(2014). Franz Rosenzweig's Conversions. World Denial and World Redemption. Bloomington-Indianapolis: Indiana University Press.

Rosenzweig, Franz (1979). Der Mensch und sein Werk. Gesammelte Schriften I. Briefe und Tagebücher. 1. Band 1900-1918. Haag: Martinus Nijhoff.

-(1979b). Der Mensch und sein Werk. Gesammelte Schriften I. Briefe und Tagebücher. 2. Band 1918-1929. Haag: Martinus Nijhoff.

(1984). Der Mensch und sein Werk. Gesammelte Schriften III. Zweistromland. Kleinere Schriften zu Glauben und Denken. Haag: Martinus Nijhoff.

-(1997). La estrella de la redención. Salamanca: Sígueme.

-(1998). «Introducción a los escritos judíos de Hermann Cohen». Judaísmo y límites de la Modernidad. Barcelona: Ríopiedras.

-(2005). «El nuevo pensamiento. Observaciones adicionales a La Estrella de la Redención». El nuevo pensamiento. Seis ensayos introductorios al pensamiento de Rosenzweig. Ed. Garrido Maturano, Á. E. Buenos Aires: Adriana Hidalgo, pp. 11-51.

-(2007). Lo humano, lo divino y lo mundano. Buenos Aires: Lilmod-Araucaria.

-(2010). Hegel und der Staat. Frankfurt a.M.: Suhrkamp.

-(2014). El país de los dos ríos. El judaísmo más allá del tiempo y de la historia. Madrid: Encuentro.

-(2015). Escritos sobre la guerra. Salamanca: Sígueme.

-(2017). Cartas sobre judaismo y cristianismo. Salamanca: Sígueme.

Schmitt, Carl (1995). Staat, Großraum, Nomos. Arbeiten aus den Jahren 1916-1969. Ed. G. Machske, Berlin: Duncker \& Humblot.

-(2002). El nomos de la Tierra en el Derecho de Gentes del "Ius publicum europaeum". Granada: Comares.

-(2004). El Leviathan en la teoría del Estado de Tomas Hobbes. Granada: Comares.

-(2007). Tierra y mar. Una reflexión sobre la historia universal. Madrid: Trotta.

Storme, Tristan (2008). Carl Schmitt et le marcionisme. L'impossibilité théologico-politique d'un ecuménisme judéo-chrétien? Paris: Cerf.

Taubes, Јасов (2007). La teología política de Pablo. Madrid: Trotta.

-(2007b). Del culto a la cultura. Elementos para una crítica de la razón histórica. Buenos Aires: Katz.

ÉNDOXA: Series Filosóficas, n. ${ }^{\circ}$ 40, 2017, pp. 183 - 202. UNED, Madrid 
Villacañas, José Luis (2008). Poder y conflicto. Ensayos sobre Carl Schmitt. Madrid: Biblioteca Nueva.

-(2016). Teología política imperial y comunidad de salvación cristiana. Una genealogía de la división de poderes. Madrid: Trotta.

-(2016b). «Hegel y Rosenzweig: apuntes sobre la crisis de Weimar». La herida del concepto. Estudios en homenaje al Profesor Félix Duque. Madrid: UAM Ediciones, pp. 383-404.

Recibido : 18/05/2017

Aceptado : 01/08/2017

\section{(C) (1) (9)}

ENDOXA está bajo una licencia de Creative Commons Reconocimiento-No-

Comercial-SinObraDerivada 4.0 Internacional 